\title{
Minimization of sink mark defects in injection molding process - Taguchi approach
}

\author{
D. Mathivanan ${ }^{1}$, M. Nouby $^{2}$ and R. Vidhya ${ }^{3}$ \\ ${ }^{1}$ Director of CAE Infotech, Chennai-600020, INDIA \\ ${ }^{2} A U / F R G$ Institute for CAD/CAM, Anna University, Chennai-600025, INDIA \\ ${ }^{3}$ Institute of Remote Sensing, Anna University, Chennai-600025, INDIA \\ E-mail: mathvan@yahoo.com (Mathivanan D.); *Corresponding author
}

\begin{abstract}
Optimal setting up of injection molding process variables plays a very important role in controlling the quality of the injection molded products. It is all the most important to control attribute defects like sink marks. Sink marks are basically a "designed in" problem and hence it is to be attended during designs stages. Owing to certain conditions and constraints, sometimes, it is rather ignored during design stages and it is expected to be handled by molders with only instruction to 'do the best'. Handling of numerous processing variables to control defects is a mammoth task that costs time, effort and money. This paper presents a simple and efficient way to study the influence of injection molding variables on sink marks using Taguchi approach. Using the Taguchi approach, optimal parameter settings and the respective sink depth were arrived. The sink depth based on the validation trials was compared with the predicted sink depth and they are found to be in good agreement. The results demonstrate the ability of this approach to predict sink depth for various combination of processing variables with in the design space.
\end{abstract}

Keywords: Sink mark, plastic injection molding, Taguchi optimization, process optimization, attribute defects in injection molding

\section{Introduction}

Injection molding is one of the major net shape forming processes for thermoplastic polymers. Over $30 \%$ of all the plastic parts manufactured are by injection molding. Injection molding is ideally suited for manufacturing large quantities of mass produced plastic parts of complex shapes and sizes. In the injection molding process, hot melt of plastic is forced into a cold empty cavity of desired shape called mold. Then, the hot melt is allowed to solidify. Solidified net shape product is ejected out of the mold upon opening. Although the process is simple, prediction of final part quality is a complex phenomenon due to the numerous processing variables. Common defects in injection molding process can be classified in to two ways. They are:

1. Dimensional related

2. Attribute related

Dimensional related defects can be controlled by correcting the mold dimensions. But, attribute related defects are generally dependent on the processing parameters. Some of the common attribute related defects are splay marks, sink marks, voids, weld/meld lines, poor surface finish, air traps, burn marks etc. Of all attribute defects, sink marks are considered to be perennial.

Sink marks can be defined as 'an unwanted depression or dimple on the surface of molding due to localized shrinkage'. The sink marks can be minimized by optimizing the process parameter settings. The process parameter settings were traditionally based on operator's experiences.

A great deal of research is being carried out to understand, identify critical factors and possibly to optimize the molding process. Most of the work carried out in the last decade was based on: theoretical, computer aided engineering based simulation models and practical experimental trials (Kazmer, 1997). Shi and Gupta (1998) tried to predict sink mark depths using localized shrinkage 
analysis through finite element methods. They also tried to establish approximate empirical equations based on the rib geometry, packing time and packing pressure (Shi and Gupta, 1999). But, other parameters like melt temperature, mold temperature, etc were not considered. Predicted Sink mark depths were observed to be smaller than the actual. Dan Tursi and Bistany (2000) attempted to study the effect of tooling factors like kind of mold material, gate type in addition to some processing parameters. In their study, barrel temperature was considered instead of melt temperature. It was observed that, gate design did not significantly contribute to sink marks but choice of mold material did significantly influence sink marks. Iyer and Ramani (2002) in an attempt to study the use of an alternate high thermal conductivity mold material, sink mark defect was taken up as quality control parameter. Using finite element method, an attempt was made to a study sink marks. It was observed that thermal conductivity of the mold material does influence sink marks.

DOE has been widely used by various researchers for optimization of injection molding process to control defects and improve quality. Patel and Mallick (1998) applied DOE for defect reduction in injection molding. Sink index was included as one of the quality indicators for investigation as part of their study. Processing variables like melt temperature, injection time, ejection temperature, fill/pack switch over, pack time, injection rate and coolant temperature were considered. Effect of mold temperature, rib-to-wall ratio and rib distance from feed point were ignored. Erzurumlu and Ozcelik (2006) used Taguchi technique to minimize warpage and the sink index. In their study, certain processing variables like mold temperature, melt temperature, packing pressure, rib cross section and rib layout (orientation) were considered. Shen et.al. (2007) made an investigation on effect of molding variables on sink mark index using Taguchi's fractional factorial design methodology. Shen et.al. considered melt temperature, mold temperature, injection time, pack time, distance between gate and rib and global increase of thickness. Mathivanan and Parthasarathy (2009a, 2009b) reported comprehensive modeling of sink marks using DOE based regressions.

The detailed literature survey indicates the following:

1. Though comprehensive studies on the effects of molding variables on sink marks do exist, a simple to use method for the molders is still required on the same lines. An approach like Taguchi method by applying a comprehensive approach as proposed (Mathivanan and Parthasarathy, 2009a, 2009b) will be of quick use to the molders.

2. Most of the Taguchi based studies used sink mark index or sink index as the parameter. It is an indirect measure for the sink marks. The sink index is an indication of the potential shrinkage due to a hot core. However, whether or not the shrinkage would result in sink mark depends on geometry characteristics (MPI user guide, MoldFlow). Hence, need for a study on sink using sink mark depth as direct response does arise.

Hence the present work was aimed at:

1. Conducting a comprehensive study on effects of variables on sinks using sink mark depth as direct response.

2. Bringing out an easy to use methodology like Taguchi, suitable for molders as well as designers, for control of sink marks.

Conducting comprehensive study on injection molding process using conventional practical approach is very expensive and also time consuming. With the advent of CAE technology, numerical simulation of injection molding process, comparatively less expensive and quicker trial runs can be experimented virtually (Mathivanan and Parthasarathy, 2008). Hence, in this research, it is proposed to employ Taguchi's design of experiments in combination with computer aided engineering (CAE) based simulated experimental data for investigation.

\section{Materials and methods}

Different steps involved in the methodology are as follows:

1. Design of simple and scalable generic model

2. Selection of processing variables and their levels

3. Initial screening Taguchi's experiments, data collection and analysis

4. Arriving at critical variables based on initial screening

5. Additional expanded Taguchi's experiments for minimization of sink marks

2.1. Design of simple, scalable and generic model and machine selection: A simple and scalable disc part (Figure 1) was prepared using Pro/Engineer. The model base wall was fixed at $3 \mathrm{~mm}$. The model was constructed in such a way that, it had 3 different rib thicknesses $(1.5 \mathrm{~mm}, 1.95 \mathrm{~mm}$ and $2.4 \mathrm{~mm})$ having rib-to-wall ratios of $50 \%, 65 \%$ and $80 \%$. The ribs were located at three levels from the feed point $(15 \mathrm{~mm}, 40 \mathrm{~mm}$ and $65 \mathrm{~mm})$. Distance between ribs $(25 \mathrm{~mm})$ was calculated to maintain a minimum distance of 10 times the maximum thickness of rib $(2.4 \mathrm{~mm})$. This is required to isolate effects of neighborhood ribs on sink mark.

2.1.1 Molding material and machine: Commercially available, amorphous, Cycolac AR ABS Co-Polymer from GE Plastics and a generic injection molding machine with 7000T clamping tonnage capable of applying $180 \mathrm{MPa}$ injection pressure were selected for the study. Properties of the Cycolac resin are given in Table -1 . 
2.1.2 Taguchi methodology: Taguchi techniques were developed by Dr. Genichi Taguchi. Taguchi developed the foundations of robust design and validated its basic philosophies by applying them in the development of many products (Phadke, 1989). Taguchi method can be used for optimization methodology that improves the quality of existing products and processes and simultaneously reduces their costs very rapidly, with minimum engineering resources and development man-hours. It achieves this objective by making the product or process performance "insensitive" to variations in factors such as materials, manufacturing equipment, workmanship and operating conditions. It also makes the product or process robust and therefore it is called as robust design.

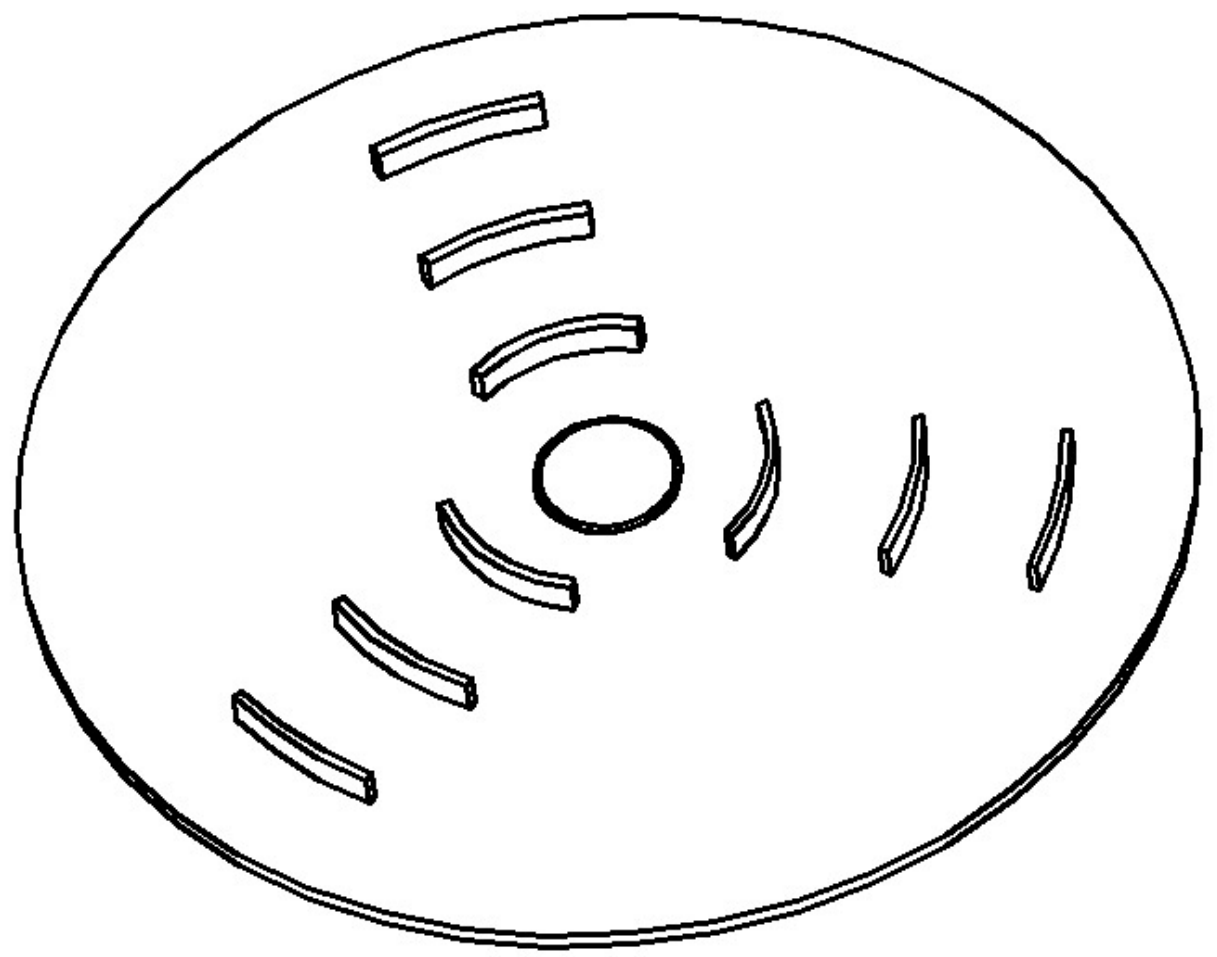

Figure 1. Disc part

Table-1 Properties of cycolac AR ABS Material

\begin{tabular}{|lc|}
\hline Properties of the Material & Cycolac AR \\
\hline Commercial product name & 1.0541 \\
\hline Solid Density $\left(\mathrm{g} / \mathrm{cm}^{3}\right)$ & 0.94383 \\
\hline Melt Density $\left(\mathrm{g} / \mathrm{cm}^{3}\right)$ & $\mathrm{VI}(240) 0234$ \\
\hline MoldFlow Viscosity index & 60 \\
\hline Recommended Mold Temperature ${ }^{\circ} \mathrm{C}$ & 240 \\
\hline Recommended Melt Temperature ${ }^{\circ} \mathrm{C}$ & Amorphous \\
\hline Material Characteristics & 108 \\
\hline Ejection Temperature ${ }^{\circ} \mathrm{C}$ & 2240 \\
\hline Modulus of Elasticity Mpa & 0.392 \\
\hline Poisson ratio & 804.6 \\
\hline Shear Modulus & $0.27 @ 2408 \mathrm{C}$ \\
\hline Thermal Conductivity W/m- $\mathrm{C}^{\circ}$ & \\
\hline
\end{tabular}

All man-made machines or set-up are classified as engineering systems according to Taguchi. Engineering systems can be classified in to two categories: 1. Static and 2. Dynamic. Dynamic system has signal factors (input from the end user) in addition to control and noise factors, whereas in static system signal factors are not present. Optimization of injection molding process is a static system (Refer Figure 2). Figure 2 is called the P-diagram. The 'P' means process or product according to Taguchi. 


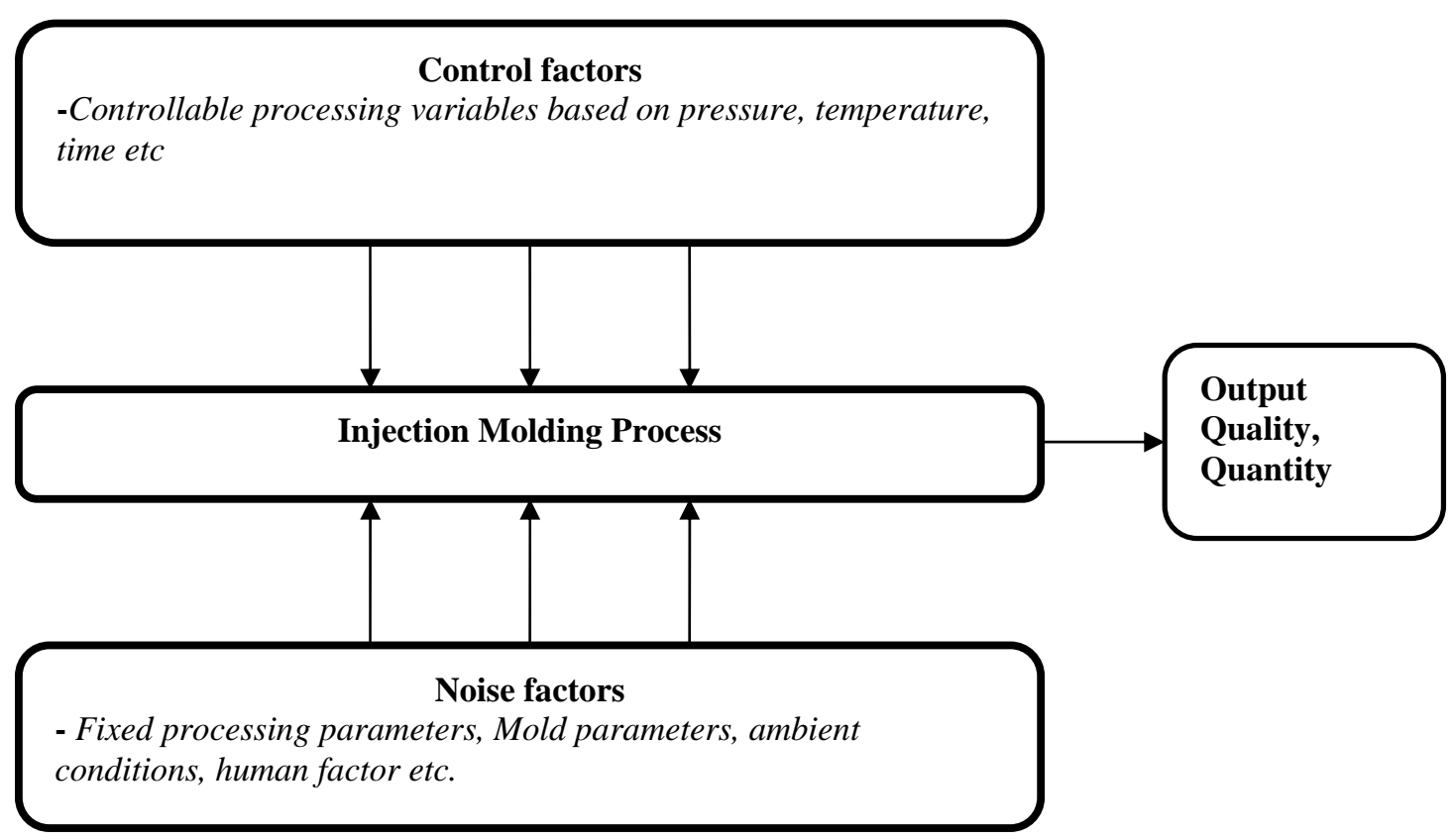

Figure 2. P-diagram of injection moulding process

Taguchi views design of any system as a three phase program: 1. System design, 2. Parameter design and 3. Tolerance design. Genesis of new idea, concepts, processes etc., due to technological advancements, comes under system design. Technological advantage gained by a new system design can be lost quickly when competitors produce the same idea in a more uniform manner. Hence, as a holistic approach, one needs to incorporate parameter design as well as tolerance design. Parameter design improves product/process uniformity and can be used to cost savings at no cost. This means that certain parameters are set to make the performance less sensitive to causes of variations. Tolerance design phase improves quality at a minimal cost (Ross, 1996). Few recent successful attempts using Taguchi's approach for modelling and analysis of abrasive wear performance of composites and parameter optimization of end milling can be seen from Mahapatra and Chaturvedi (2009) and Sanjit et.al. (2010).

In this present work, parameter design is utilized to arrive at the optimum levels of process parameters for minimization of sink depth/mark during manufacturing. According to Taguchi, two major tools are employed to achieve any quality goal or any robust design. They are: 1 . Signal -to- Noise ratio ( $\mathrm{S} / \mathrm{N}$ ratio), which measures quality and 2. Orthogonal arrays, which are used to study many parameters simultaneously (Phadke, 1989)

Taguchi uses the $\mathrm{S} / \mathrm{N}$ ratio to measure quality characteristic deviating from the desired value. The $\mathrm{S} / \mathrm{N}$ ratio characteristics can be divided into three categories: the-nominal-the-best, the smaller-the-better, and the-larger-the-better when the quality characteristic is continuous (Ross, 1996). Since, the objective of this study was to minimize the sink mark depth; smaller-the-better quality characteristic was employed. Two orthogonal arrays (OA) were used for experiments. One OA is used for initial screening of processing variables and the other to arrive at optimal process conditions.

2.1.3 Experimental set-up: In order to mold a component on the injection molding machine, a proper mold based on good mold design is required. Mold design basically involves designing of feed system to feed the material from the machine nozzle into the mold cavity, cooling systems to solidify the product after injection and clamping system to keep the mold closed during pressurized injection. Feed system consists of sprue, runner and gate. Cooling system consists of cooling channels and it should be capable of maintaining the required mold temperature. For the present study, Tapered central sprue (4mm diameter) feed point, Disc type runner $(4 \mathrm{~mm})$ and diaphragm gate $(1 \mathrm{~mm})$ were designed to have uniform flow based on standard mould design guide lines. Twelve diameter cooling channels were designed for efficient maintenance of mold temperature.

The 3D Model, made using Pro/E, was exported to computer aided Simulation tool (in this study MoldFlow was used). Mid plane finite element model was created by meshing the 3D model with 1684 linear triangular elements. Average aspect ratio of the mesh was found to be 1.528. Mesh was thoroughly checked to eliminate mesh related errors. Feed system and cooling channels were created as designed earlier. This set-up was used for conducting trials. Meshed models are shown in Figure 3. 


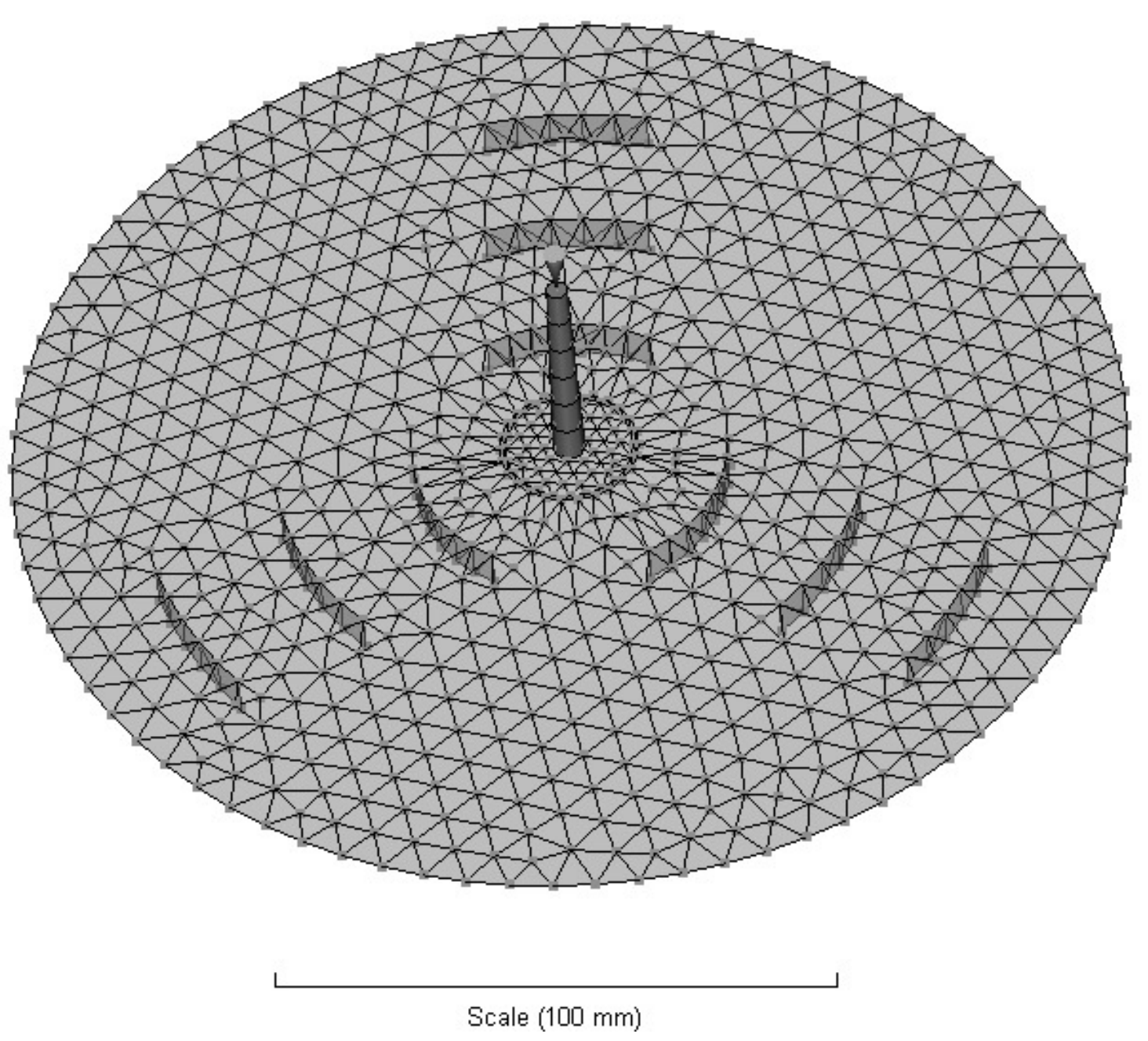

Figure 3. Meshed model of the disc part

2.2 Selection of processing variables and their levels: Based on the detailed literature survey, extensive discussion with molders and through one initial trial, the following processing parameters were considered for the initial screening experiments (Table -2).

Table: 2 Initial screening parameters and their levels

\begin{tabular}{|c|c|l|c|c|}
\hline \multirow{2}{*}{ Number } & \multirow{2}{*}{$\begin{array}{c}\text { Coded } \\
\text { Parameters }\end{array}$} & \multicolumn{1}{|c|}{ Uncoded Parameters } & \multicolumn{2}{|c|}{ Levels } \\
\cline { 3 - 5 } & & Low (1) & High (2) \\
\hline 1 & $\mathrm{~A}$ & Melt Temperature $\left({ }^{\circ} \mathrm{C}\right)$ & 220 & 260 \\
\hline 2 & $\mathrm{~B}$ & Mould Temperature $\left({ }^{\circ} \mathrm{C}\right)$ & 40 & 80 \\
\hline 3 & $\mathrm{C}$ & Injection Time $(\mathrm{sec})$ & 1.20 & 1.80 \\
\hline 4 & $\mathrm{D}$ & Packing Time $(\mathrm{sec})$ & 8 & 29 \\
\hline 5 & $\mathrm{E}$ & Packing Pressure (MPa) & 23 & 80 \\
\hline 6 & $\mathrm{~F}$ & Rib-to-wall Ratio (\%) & 50 & 65 \\
\hline 7 & $\mathrm{G}$ & $\begin{array}{l}\text { Rib Distance from gate } \\
(\mathrm{mm})\end{array}$ & 15 & \\
\hline
\end{tabular}

\section{Injection molding experiments}

3.1 Initial screening Taguchi's experiments, data collection and analysis: Taguchi L8 screening experiments were conducted to identify the "most significant" input variables by ranking with respect to their relative impact on the sink mark. Table -3 shows the Taguchi's array for L8 experimental runs. 
The $\mathrm{S} / \mathrm{N}$ ratio $\eta$ is given by:

$$
\eta=-10 \log (M S D)
$$

Where MSD is the mean-square deviation for the output characteristic. MSD for the smaller-the-better quality characteristic is calculated by the following equation,

$$
M S D=\frac{1}{N}\left[\sum_{i=1}^{n} Y_{i}^{2}\right]
$$

Where $\mathrm{Y}_{\mathrm{i}}$ is the sink mark depth for the $\mathrm{i}^{\text {th }}$ test, $\mathrm{n}$ denotes the number of tests and $\mathrm{N}$ is the total number of data points. The function '-log' is a monotonically decreasing one, it means that we should maximize the $\mathrm{S} / \mathrm{N}$ value. The $\mathrm{S} / \mathrm{N}$ values were calculated using equations (1) and (2). Table -4 shows the response table for $\mathrm{S} / \mathrm{N}$ ratios using smaller-the-better approach.

Table-3 Taguchi L8 Array

\begin{tabular}{|c|l|l|l|l|l|l|l|}
\hline Run & A & B & C & D & E & F & G \\
\hline $\mathbf{1}$ & 1 & 1 & 1 & 1 & 1 & 1 & 1 \\
\hline $\mathbf{2}$ & 1 & 1 & 1 & 2 & 2 & 2 & 2 \\
\hline $\mathbf{3}$ & 1 & 2 & 2 & 1 & 1 & 2 & 2 \\
\hline $\mathbf{4}$ & 1 & 2 & 2 & 2 & 2 & 1 & 1 \\
\hline $\mathbf{5}$ & 2 & 1 & 2 & 1 & 2 & 1 & 2 \\
\hline $\mathbf{6}$ & 2 & 1 & 2 & 2 & 1 & 2 & 1 \\
\hline $\mathbf{7}$ & 2 & 2 & 1 & 1 & 2 & 2 & 1 \\
\hline $\mathbf{8}$ & 2 & 2 & 1 & 2 & 1 & 1 & 2 \\
\hline
\end{tabular}

Table -4 Response table for $\mathrm{S} / \mathrm{N}$ ratios using smaller-the-better

\begin{tabular}{|c|c|c|c|c|c|c|c|}
\hline Level & $\begin{array}{c}\text { Melt } \\
\text { temperature }\end{array}$ & $\begin{array}{c}\text { Mold } \\
\text { Temperature }\end{array}$ & $\begin{array}{c}\text { Injection } \\
\text { Time }\end{array}$ & $\begin{array}{c}\text { Packing } \\
\text { Time }\end{array}$ & $\begin{array}{c}\text { Packing } \\
\text { Pressure }\end{array}$ & $\begin{array}{c}\text { Rib-to- } \\
\text { Wall ratio }\end{array}$ & $\begin{array}{c}\text { Rib } \\
\text { Distance }\end{array}$ \\
\hline 1 & 25.72 & 27.55 & 26.58 & 26.42 & 26.66 & 28.13 & 29.96 \\
\hline 2 & 27.73 & 25.90 & 26.87 & 27.03 & 26.80 & 25.33 & 23.49 \\
\hline Delta & 2.01 & 1.64 & 0.30 & 0.61 & 0.14 & 2.80 & 6.47 \\
\hline Rank & 3 & 4 & 6 & 5 & 7 & 2 & 1 \\
\hline
\end{tabular}

3.2 Parameters selection for follow-up experiments: It was found that, rib distance made significant contribution in the formation of sinks followed by Rib-to-Wall ratio, melt temperature, mold temperature, packing pressure, packing time and injection time. After this initial screening and ranking, it was decided to treat injection time and pack pressure as fixed parameters. The Injection time was fixed at $1.2 \mathrm{sec}$. The pack pressure was fixed at $26 \mathrm{MPa}$. These decisions were taken under the consideration of overall quality and economics in mind.

Maintaining higher pack pressure requires additional power and cost. Packing a part with higher pressure normally leads to higher residual stress and it was not desirable. Though the ranking for pack time was the lowest, it was included in the follow-up experiments to study its impact.

3.3 Taguchi L27 follow-up experiments, data collection and analysis: During the follow-up experiments for minimization, processing variables were considered at three levels. Table -5 shows the variables and its levels considered for the follow-up experiments. 
Table - 5 Follow-up experiment variables and its levels

\begin{tabular}{|c|c|l|c|c|c|}
\hline \multirow{2}{*}{ Number } & \multirow{2}{*}{$\begin{array}{c}\text { Coded } \\
\text { Parameters }\end{array}$} & \multicolumn{2}{|c|}{ Uncoded Parameters } & \multicolumn{3}{|c|}{ Levels } \\
\cline { 3 - 5 } & & Low (1) & Mid (2) & High (3) \\
\hline 1 & $\mathrm{~A}$ & Melt Temperature $\left({ }^{\circ} \mathrm{C}\right)$ & 220 & 240 & 260 \\
\hline 2 & $\mathrm{~B}$ & Mold Temperature $\left({ }^{\circ} \mathrm{C}\right)$ & 40 & 60 & 1.80 \\
\hline 3 & $\mathrm{D}$ & Packing Time $(\mathrm{sec})$ & 8 & 10 & 12 \\
\hline 4 & $\mathrm{~F}$ & Rib-to-wall Ratio $(\%)$ & 50 & 65 & 80 \\
\hline 5 & $\mathrm{G}$ & $\begin{array}{l}\text { Rib Distance from gate } \\
(\mathrm{mm})\end{array}$ & 15 & 40 & 65 \\
\hline
\end{tabular}

Twenty seven experiments were conducted and all the sink mark data points were collected. Collected data points were analyzed using the "smaller-the-better approach". The $\mathrm{S} / \mathrm{N}$ ratios were calculated using equations (1) and (2). Response table for signal to noise ratio was constructed (Table - 6). Main effects plot for $\mathrm{S} / \mathrm{N}$ ratio is shown in Figure 4.

Table -6 S/N ratio table for follow-up experiments

\begin{tabular}{|c|c|c|c|c|c|c|c|}
\hline $\begin{array}{c}\text { Experimental } \\
\text { Run }\end{array}$ & $\begin{array}{c}\text { Melt } \\
\text { Temperature } \\
\text { (A) }\end{array}$ & $\begin{array}{c}\text { Momperature } \\
\text { (B) }\end{array}$ & $\begin{array}{c}\text { Pack } \\
\text { Time } \\
\text { (D) }\end{array}$ & $\begin{array}{c}\text { Rib-to-wall } \\
\text { Ratio } \\
\text { (F) }\end{array}$ & $\begin{array}{c}\text { Rib } \\
\text { Distance } \\
\text { (G) }\end{array}$ & $\begin{array}{c}\text { Sink } \\
\text { Depth } \\
\text { In mm }\end{array}$ & S/N ratio \\
\hline 1 & 220 & 40 & 8 & 50 & 15 & 0.025460 & 31.883003 \\
\hline 2 & 220 & 40 & 10 & 65 & 40 & 0.056458 & 24.965459 \\
\hline 3 & 220 & 40 & 12 & 80 & 65 & 0.088900 & 21.021965 \\
\hline 4 & 220 & 60 & 8 & 65 & 65 & 0.088617 & 21.049620 \\
\hline 5 & 220 & 60 & 10 & 80 & 15 & 0.036564 & 28.739021 \\
\hline 6 & 220 & 60 & 12 & 50 & 40 & 0.053858 & 25.374947 \\
\hline 7 & 220 & 80 & 8 & 80 & 40 & 0.065347 & 23.695474 \\
\hline 8 & 220 & 80 & 10 & 50 & 65 & 0.083950 & 21.519555 \\
\hline 9 & 220 & 80 & 12 & 65 & 15 & 0.038355 & 28.323470 \\
\hline 10 & 240 & 40 & 8 & 50 & 15 & 0.020054 & 33.955980 \\
\hline 11 & 240 & 40 & 10 & 65 & 40 & 0.043997 & 27.131460 \\
\hline 12 & 240 & 40 & 12 & 80 & 65 & 0.074100 & 22.603636 \\
\hline 13 & 240 & 60 & 8 & 65 & 65 & 0.072478 & 22.795864 \\
\hline 14 & 240 & 60 & 10 & 80 & 15 & 0.030481 & 30.319444 \\
\hline 15 & 240 & 60 & 12 & 50 & 40 & 0.042833 & 27.364450 \\
\hline 16 & 240 & 80 & 8 & 80 & 40 & 0.058235 & 24.696393 \\
\hline 17 & 240 & 80 & 10 & 50 & 65 & 0.068565 & 23.277988 \\
\hline 18 & 240 & 80 & 12 & 65 & 15 & 0.032409 & 29.786687 \\
\hline 19 & 260 & 40 & 8 & 50 & 15 & 0.022367 & 33.007923 \\
\hline 20 & 260 & 40 & 10 & 65 & 40 & 0.037175 & 28.595051 \\
\hline 21 & 260 & 40 & 12 & 80 & 65 & 0.063400 & 23.958215 \\
\hline 22 & 260 & 60 & 8 & 65 & 65 & 0.061962 & 24.157519 \\
\hline 23 & 260 & 60 & 10 & 80 & 15 & 0.031746 & 29.966247 \\
\hline 24 & 260 & 60 & 12 & 50 & 40 & 0.035834 & 28.914167 \\
\hline 25 & 260 & 80 & 8 & 80 & 40 & 0.062701 & 24.054469 \\
\hline 26 & 260 & 80 & 10 & 50 & 65 & 0.060334 & 24.388815 \\
\hline 27 & 260 & 80 & 12 & 65 & 15 & 0.033013 & 29.626353 \\
\hline
\end{tabular}

\section{Results and discussion}

From the Table -6 and from main effects plot for $\mathrm{S} / \mathrm{N}$ ratio (Figure 4), it is observed that, rib distance from the feed point is a most influential variable on sink. This factor needs to be considered while designing the part as well as during mold design. If the feed points cannot be provided near a rib, flow leaders can be designed in to the component. This could be an important input to product designers. 


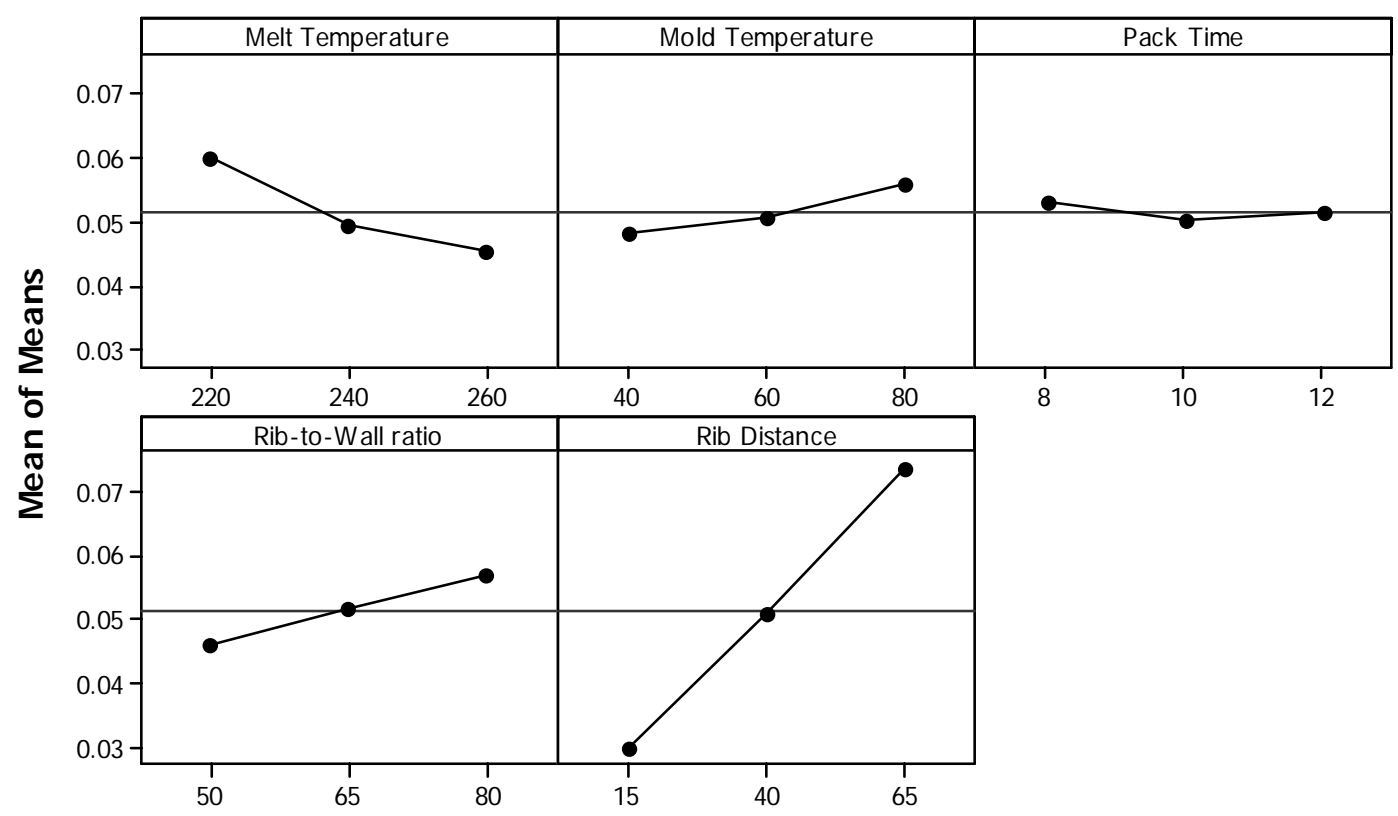

Figure 4. Main effects plot

The prime objective of this study was to find optimum level for each of the variables and to arrive at a combination of these factors that could result in minimum sink. From figure. 4, it can be observed that A3-B1-D2-F1-G1 is the optimum combination for minimum sink depth. Similarly, A1-B3-D1-F3-G3 is the combination for maximum sink depth. These combinations were not included in the experimental runs. Hence, additional two confirmation experiments were run at both combinations. The results are shown in Table 7.

Table -7 Verification experimental results

\begin{tabular}{|c|c|c|c|c|c|c|c|c|c|}
\hline $\begin{array}{c}\text { Validation } \\
\text { Run }\end{array}$ & A & B & D & F & G & $\begin{array}{c}\text { S/N } \\
\text { ratio }\end{array}$ & $\begin{array}{c}\text { Predicted } \\
\text { Sink } \\
\text { Depth }\end{array}$ & $\begin{array}{c}\text { Measured } \\
\text { Sink } \\
\text { Depth }\end{array}$ & $\begin{array}{c}\text { \% } \\
\text { Deviation }\end{array}$ \\
\hline 1 & 260 & 40 & 10 & 50 & 15 & 33.5847 & 0.0164416 & 0.0154293 & $6.2 \%$ \\
\hline 2 & 220 & 80 & 8 & 80 & 65 & 20.2139 & 0.0939485 & 0.0897736 & $4.4 \%$ \\
\hline
\end{tabular}

As is seen from the Table 7, the difference or the variation between the predicted and measured sink depth is well below $10 \%$. It shows the adequacy of the approach in prediction of the sink depth.

Authors have also continued the research with regression analysis and further analyses on the prediction and minimization of the sink marks. Those analyses and findings are not included in this work, as they have been performed in a different study.

\section{Conclusion}

Manipulation of numerous processing variables of the injection moulding process to control defects is a mammoth task that costs time, effort and money. This paper presents a simple and efficient way to study the influence of injection molding variables on sink marks using Taguchi approach. Application of Taguchi approach also helps in arriving at optimal parameter settings. The sink depth through the validation trials based on the optimal parameters and the predicted sink depth using Taguchi's approach for the same settings are found to be in good agreement. The results show the ability of this approach to predict sink depth for various combination of processing variables with in the design space. It is observed that, increased distance of rib from the feed point seems to produce deeper sinks. This could be an important input to product designers for designing alternatives or to give effective and corrective solutions. This methodology can also be applied while designing parts. Though this study was meant for the sink marks, it can be extended to other defects and also for improving overall quality. 


\section{Nomenclature}

$\begin{array}{lll}\% & - & \text { Percent } \\ { }^{\circ} \text { C } & - & \text { Degree centigrade } \\ \eta & - & \text { The S/N ratio } \\ \text { 3D } & - & \text { Three Dimension } \\ \text { ABS } & - & \text { Acrylonitrile Butadiene Styrene } \\ \text { ANN } & - & \text { Artificial Neural Network } \\ \text { ANOVA } & - & \text { Analysis of Variance } \\ \text { A } & - & \text { Melt Temperature in }{ }^{\circ} \mathrm{C} \\ \text { B } & - & \text { Mold Temperature in }{ }^{\circ} \mathrm{C} \\ \text { C } & - & \text { Injection Time in sec } \\ \text { CAD } & - & \text { Computer Aided Design } \\ \text { CAE } & - & \text { Computer Aided Engineering } \\ \text { D } & - & \text { Packing time in sec } \\ \text { DOE } & - & \text { Design of Experiments } \\ \text { E } & - & \text { Packing Pressure in MPa } \\ \text { F } & - & \text { Rib-to-wall Ratio in } \% \\ \text { FE } & - & \text { Finite Element } \\ \text { FEA } & - & \text { Finite Element Analysis } \\ \text { G } & - & \text { Rib Distance from gate in } \mathrm{mm} \\ \text { mm } & - & \text { millimetres } \\ \text { MPa } & - & \text { Mega Pascal } \\ \text { MSD } & - & \text { Mean square deviation } \\ \text { N } & - & \text { Total number of data points } \\ \text { sec } & - & \text { Seconds }\end{array}$

\section{References}

Erzurumlu T. and Ozcelik B. 2006. Minimization of warpage and sink index in injection-molded thermoplastic parts using Taguchi optimization method. Materials and Design, Vol. 27, pp. 853-861.

Iyer N. and Ramani K. 2002. A study of localized shrinkage in injection molding with high thermal conductivity molds. Journal of Injection Molding Technology, Vol. 6, No.2, pp. 73-90.

Kazmer D., 1997. The foundation of intelligent process control for injection molding. Journal of Injection Molding Technology, Vol. 1, No.1, pp. 44-56.

Mahapatra S.S. and Chaturvedi V. 2009, Modelling and analysis of abrasive wear performance of composites using Taguchi approach. International Journal of Engineering, Science and Technology, Vol. 1, No. 1, 2009, pp. 123-135

Mathivanan D. and Parthasarathy N.S. 2008. Sink mark prediction and optimization - a review. Society of Plastics Engineers ANTEC 2008, Milwaukee, USA

Mathivanan D. and Parthasarathy N.S. 2009a. Prediction of sink depths using non-linear modeling of injection molding variables. International Journal of Advanced Manufacturing Technology, Springerlink, Vol. 43, pp. 654-663.

Mathivanan D. and Parthasarathy N.S. 2009b. Sink-mark minimization in injection molding through response surface regression modeling and genetic algorithm. International Journal of Advanced Manufacturing Technology, Springerlink, Vol. 45, pp. 867874.

Moldflow MPI user guide. 2005. Moldflow, Waltham, MA, US.

Moshat S., Datta S., Bandyopadhyay A. and Pal P.K. 2010. Parametric optimization of CNC end milling using entropy measurement technique combined with grey-Taguchi method, International Journal of Engineering, Science and Technology, Vol. 2, No. 2, 2010, pp. 1-12

Patel S.A. and Mallick P.K. 1998. Development of a methodology for defect reduction in injection molding using process simulations Journal of Injection Molding Technology, Vol. 2, No. 4, pp176-191.

Phadke M.S.. 1989. Quality Engineering Using Robust Design, Prentice Hall, NJ,US

Ross P.J.. 1996. Taguchi Techniques for Quality Engineering. McGraw-Hill, NY, US

Shen, C., Wang, L., Cao W. and Qian L. 2007. Investigation of the effect of molding variables on sink marks of plastic injection molded parts using Taguchi's DOE technique. Polymer -Plastics Technology and Engineering, Vol. 46, No. 3, pp. 219-225.

Shi L. and Gupta M. 1998. A localized shrinkage analysis for predicting sink marks in injection-molded plastic parts. Journal of Injection Molding Technology, Vol. 2, No. 4, pp149-155.

Shi L. and Gupta M. 1999. An approximate prediction of sink mark depth in rib-reinforced plastic parts by empirical equations. Journal of Injection Molding Technology, Vol. 3, No. 1, pp 1-10. 
Tursi D. and Bistany S. P. 2000. Process and tooling factors affecting sink marks for amorphous and crystalline resins. Journal of Injection Molding Technology, Vol. 4, No. 3, pp.114-119.

\section{Biographical notes}

Dr. D. Mathivanan is a Practicing Engineer in the field of Mechanical Engineering. He obtained his B.E. (Mechanical) from GCT, Coimbatore, India in the year 1990. He received his M.E. (Manufacturing) and Ph.D. from Anna University, Chennai, India. He has international, national journals and conference papers to his credit. His research areas are CAD, CAM, CAE and Plastics.

M. Nouby is a Research Scholar in the Department of Mechanical Engineering, Anna University, India since 2007. He received his B.Sc. and M.S. degrees from Department of Automotive and Tractor Engineering, Minia University, Egypt in 1999 and 2003 respectively. Prior to joining the faculty at Anna University, he worked as an Assistant Lecturer in Minia University from 2003 to 2007. His research interests are in the areas of Vehicle Dynamics, Finite Element Methods, Automotive Design, Noise and Vibration.

Dr. R. Vidhya is an Assistant Professor in the Institute of Remote Sensing, Department of Civil Engineering of Anna University. She has many international and national journals and conference papers to her credit. She is currently dealing with numerous projects sponsored by Department of Space, Government of India. Her current research interests are Climate change, Object identification, GIS, RS and Optimization techniques.

Received December 2009

Accepted January 2010

Final acceptance in revised form February 2010 